\title{
Understanding the AC conductivity and permittivity of trapdoor chabazites for future development of next-generation gas sensors
}

\author{
Hélène Bordeneuve ${ }^{1, *}$, Dominic J. Wales ${ }^{2, *},{ }^{*}$, Andrew J.W. Physick ${ }^{2}$, Huan V. Doan ${ }^{3,4}$, \\ Valeska P. Ting ${ }^{3} \&$ Chris R. Bowen ${ }^{1, t}$ \\ 1. Department of Mechanical Engineering, University of Bath, Claverton Down, Bath, Somerset, BA2 7AY, U.K. \\ 2. Department of Chemical Engineering, University of Bath, Claverton Down, Bath, Somerset, BA2 7AY, U.K. \\ 3. Department of Mechanical Engineering, University of Bristol, Bristol, BS8 1TR, U.K. \\ 4. Department of Oil Refining and Petrochemistry, Faculty of Oil and Gas, Hanoi University of Mining and Geology, Duc \\ Thang, Bac Tu Liem, Hanoi, Vietnam.
}

\begin{abstract}
Synthetic $\mathrm{K}^{+}$chabazite $(\mathrm{KCHA}), \mathrm{Cs}^{+}$chabazite $(\mathrm{CsCHA})$ and $\mathrm{Zn}^{2+}$ chabazite $(\mathrm{ZnCHA})$ have been synthesized and investigated in order to relate the differences in their crystalline structures to their thermal stability, moisture content and frequency dependent alternating current (AC) conductivity, permittivity and phase angle at a range of temperatures. The materials are shown to exhibit the universal dielectric response, which is typical of materials consisting of both conductive and insulating regions. Due to the presence of porosity the three chabazites were hydrated significantly at room temperature and so the dehydrated state was achieved by heating the chabazites to high temperatures to ensure that all different energetic types of water were removed. Cation migration activation energies for $\mathrm{KCHA}(0.66 \pm 0.10) \mathrm{eV}$, $\mathrm{CsCHA}(0.88 \pm$ $0.01) \mathrm{eV}$ and $\mathrm{ZnCHA}(0.90 \pm 0.01) \mathrm{eV}$ were determined during the cooling cycle from the fully dehydrated state to provide an accurate measurement the activation energies. Good thermal stability of the materials was observed up to $710{ }^{\circ} \mathrm{C}$ and below $200{ }^{\circ} \mathrm{C}$ the electrical properties can be strongly influenced by hydration level. Overall, it was determined that when either hydrated or dehydrated, KCHA had the highest conductivity and lowest cation migration activation energy of the three studied chabazites and thus has the most promising electrical properties for potential use as a gas sensing material in next-generation electricalbased gas sensors.
\end{abstract}

Keywords: Chabazites; conductivity; permittivity; zeolites; trapdoor.

1. Introduction

\footnotetext{
* Joint first authorship: both authors contributed equally to this work.

$\dagger$ Current Address: Faculty of Engineering, University of Nottingham, Nottingham, NG7 2RD, U.K.

${ }^{\ddagger}$ Corresponding author: Prof. Chris R. Bowen, Department of Mechanical Engineering, Claverton Down, University of Bath, Bath, Somerset, BA2 7AY, U.K. Email: c.r.bowen@bath.ac.uk Phone: +44 (0)1225 383660
} 
Zeolites are porous aluminosilicate minerals with large extra-framework sites that can incorporate both exchangeable cations and water molecules [1]. They are described by the simplified formula $\mathrm{M}_{2 / n} \mathrm{O}_{2} \mathrm{Al}_{2} \mathrm{O}_{3} . y \mathrm{SiO}_{2} . w \mathrm{H}_{2} \mathrm{O}$ where $n$ is the charge of the cation $\mathrm{M}$ and $w$ is the amount of water contained in the voids [2]. In addition, some of the $\mathrm{Si}$ and $\mathrm{Al}$ atoms can be replaced by atoms of other elements that form tetrahedral $\mathrm{TO}_{4}$ units; examples include $\mathrm{Ti}$ and $\mathrm{B}$ [3]. These materials are used in many industrial processes for adsorption, catalysis, ion exchange or as molecular sieves [4]. Zeolites have also been used as the active gas detecting element in a wide range of detector and/or sensor systems [5].

Chabazite (CHA) zeolites form one of the 82 accepted zeolite mineral topologies [6], and is an abundant natural mineral, but can also be readily synthesized [7]. The chabazite framework consists of an ordered arrangement of $\mathrm{SiO}_{4}$ and $\mathrm{AlO}_{4}$ tetrahedra forming three different types of rings, as shown in Figure 1a, which shows four (4MR), six (6DR), and eight-membered rings (8MR). Double 6-rings (6DR) are arranged in layers in an $\mathrm{ABC}$ sequence and linked by tilted 4-rings [8].

\section{Position of Figure 1a and 1b}

\section{Position of caption for Figure 1a and 1b}

The favoured positions of different cations in chabazite results in different properties for the different cation forms of chabazite, which makes chabazite materials attractive for several processes and applications. For example, in $\mathrm{CsCHA}$, the $\mathrm{Cs}^{+}$cations can act as selective aperture 'trapdoors', which have been successfully utilised for gas and gaseous isotope separations [9-11]. This selective 'trapdoor' behaviour in chabazite is a potentially attractive functional attribute in a gas selective material for sensing applications.

Previous studies $[12,13]$ of several forms of ion-exchanged chabazite show that cations may be located at four different positions: one at the center of the 6DR prism (SI), one at the entrance of the 6DR prism, but displaced relative to the supercavity (SII), one in the supercavity at the four-ring window (SIII), and one in the eight-ring window of the channel (SIII'); these are shown in Figure 1b.

In this paper we will examine synthetic chabazites containing $\mathrm{K}^{+}, \mathrm{Cs}^{+}$and $\mathrm{Zn}^{2+}$, therefore it is of interest to describe the position of these cations. At room temperature, in hydrated chabazites, the $\mathrm{K}^{+}$cations are located in the SII positions and the $\mathrm{Cs}^{+}$cations are bound primarily within the eight-member ring in the 
SIII' position [14]. According to density functional theory models, $\mathrm{Zn}^{2+}$ cations are more stable in the larger rings, with the $\mathrm{Zn}^{2+}$ cations located as six-membered rings as the most stable configuration [15]; the $\mathrm{Zn}^{2+}$ cations are likely to be more reactive in the small rings [15].

In addition, seven water sites are known. Previous electrical studies on zeolites have shown that the electrical conductivity, along with dielectric relaxation phenomena in zeolites, are strongly affected by the presence of adsorbed water [16-18] . However, after dehydration, it is expected that any measured conductivity will be due to the migration of interstitial cations, commonly alkali metal or alkaline earth metal cations [19-21]. This migratory cation behavior is also expected to occur in chabazite, however, to the best of the authors' knowledge, few studies of the electrical properties of chabazites have been published [22-25]. For example, Beattie [20] examined a range of ion-exchanged chabazites based on the natural mineral of chabazite since it could not be synthesized at that time and an increase in activation energy with increasing ionic radii was observed, which ranged from $\sim 0.65$ to $0.8 \mathrm{eV}[20]$. Barrer et al. [21] examined anhydrous and partially hydrated sodium chabazite, while Kjær et al. [22] examined sodium and lithium doped chabazites. Pressed powders of the material were used in all cases with metallic electrodes for electrical characterization $[20,21,22]$ and the measured activation energy was independent of pressing pressure [20]. There have been no such studies undertaken on the polycrystalline $\mathrm{Zn}^{2+}$ chabazite.

In this study, synthetic $\mathrm{K}^{+}$chabazite $(\mathrm{KCHA}), \mathrm{Cs}^{+}$chabazite $(\mathrm{CsCHA})$ and $\mathrm{Zn}^{2+}$ chabazite $(\mathrm{ZnCHA})$ have been investigated in order to relate the differences in their crystalline structures to their thermal stability, and frequency dependent electrical properties as a function of temperature. $\mathrm{KCHA}$ and $\mathrm{CsCHA}$ were chosen as both exhibit selective aperture trapdoor behavior for different gases [9]. ZnCHA was chosen to elucidate the effect of a divalent cation on the electrical properties of the chabazite and $\mathrm{ZnCHA}$ has also been demonstrated to exhibit greater $\mathrm{CO}_{2} / \mathrm{N}_{2}$ selectivity compared to chabazites with other divalent counter cations [26]. This is ultimately to elucidate the suitability of these chabazites as potential gas selective/sensing materials, for example in ionic conductivity based gas sensors [27]. In particular, this work utilizes impedance spectroscopy, a technique which has been previously used to investigate longrange ionic conductivity of microporous materials and to screen porous materials for sensing applications, with a focus on the alternating current (AC) conductivity, permittivity and phase angle of these chabazites, over a temperature range of $30^{\circ} \mathrm{C}$ to $710{ }^{\circ} \mathrm{C}[28,29]$. It should be noted that has been previously established, 
that neither the $\mathrm{Si} / \mathrm{Al}$ ratio, nor the diameter of crystallites would result in the observed differences in conductivity of these zeolites $[21,30,31]$

\section{Experimental section}

\subsection{Materials synthesis}

Chemicals, materials and solvents were obtained from Sigma-Aldrich or Fisher Scientific and used as obtained, unless otherwise described.

The parent chabazite (KNaCHA) was synthesized from zeolite $\mathrm{Y}$ by heating $5 \mathrm{~g}$ of zeolite $\mathrm{Y}$ in vacuo at $450{ }^{\circ} \mathrm{C}$ for $6 \mathrm{~h}$, at a heating rate of $2{ }^{\circ} \mathrm{C} \mathrm{min}^{-1}$. $\sim 4 \mathrm{~g}$ of dry zeolite $\mathrm{Y}$ was added to a solution of $31.6 \mathrm{ml}$ $\mathrm{H}_{2} \mathrm{O}$ and $4.3 \mathrm{ml} \mathrm{KOH}(45 \% \mathrm{w} / \mathrm{v})$. The resulting mixture was agitated for 30 seconds before heating at 95 ${ }^{\circ} \mathrm{C}$ for $96 \mathrm{~h}$. The overall gel composition was $0.17 \mathrm{Na}_{2} \mathrm{O}: \mathrm{Al}_{2} \mathrm{O}_{3}: 8 \mathrm{SiO}_{2}: 500 \mathrm{H}_{2} \mathrm{O}$. The product was then washed with $500 \mathrm{~mL}$ distilled water and dried at room temperature to obtain the target $\mathrm{KNaCHA}$ chabazite [32].

A $2 \mathrm{~g}$ mass of the as-synthesized chabazite was then ion-exchanged with either $1 \mathrm{M} \mathrm{KCl}$ solution $(80 \mathrm{~mL})$, $1 \mathrm{M} \mathrm{CsCl}$ solution $(80 \mathrm{~mL})$ or $1 \mathrm{M} \mathrm{ZnCl}_{2}$ solution $(40 \mathrm{~mL})$ at $70{ }^{\circ} \mathrm{C}$ with stirring for $24 \mathrm{~h}$ to produce the $\mathrm{K}$, $\mathrm{Cs}$ and $\mathrm{Zn}$ ion-exchanged CHA zeolites respectively. The products then were washed with water until the washings were at $\mathrm{pH} 7$.

\subsection{Materials Characterisation}

Powder X-ray diffractometry, for identification and phase purity determination, was performed using a Phillips SEI diffractometer with a CuK $\alpha$ source $(\lambda=1.540598 \AA$ ). Thermogravimetric analyses (TGA) was performed on a Setaram Setsys Evolution on sample masses of $\sim 5 \mathrm{mg}$. The samples were submitted to heating and cooling cycles from room temperature $\left(\sim 21^{\circ} \mathrm{C}\right)$ to $700{ }^{\circ} \mathrm{C}$ at a $5{ }^{\circ} \mathrm{C} \cdot \mathrm{min}^{-1}$ heating rate under a flow of air. Energy dispersive X-ray spectroscopy was performed using an Oxford INCA X-ray analyser attached to a JEOL SEM6480LV scanning electron microscope. 
In order to measure electrical properties, $0.5 \mathrm{~cm}$ diameter pellets consisting of the powders of the three chabazites were fabricated by compression for $c a .5 \mathrm{~min}$ at a pressure of 1 ton. $\mathrm{cm}^{-2}$. Electrical contacts were deposited onto both sides of the disks by gold sputter coating to a thickness of $c a .100 \mathrm{~nm}$.

The complex impedance $\left(Z^{*}=\mathrm{Z}^{\prime}+i \mathrm{Z}^{\prime \prime}\right)$ was measured in the frequency range $0.1 \mathrm{~Hz}-1 \mathrm{MHz}$ using a Solartron 1260 Impedance analyzer with a 1296 Dielectric Interface, over a range of temperatures from room temperature $\left(\sim 21{ }^{\circ} \mathrm{C}\right)$ to $710{ }^{\circ} \mathrm{C}$. Care was taken to ensure dehydration of the water from the chabazites by using a two phase heating profile. A heating rate of $1{ }^{\circ} \mathrm{C} \cdot \mathrm{min}^{-1}$ from $\sim 21{ }^{\circ} \mathrm{C}$ to $710{ }^{\circ} \mathrm{C}$ was initially used, with a dwell of $20 \mathrm{~min}$ at each set measurement temperature; the temperature interval was 20 ${ }^{\circ} \mathrm{C}$. After the heating phase, the dehydrated samples were subsequently cooled to room temperature and the complex impedance was measured again, as described above, from $710^{\circ} \mathrm{C}$ to $\sim 21^{\circ} \mathrm{C}$. The AC conductivity during the cooling phase was used to enable calculation of the cation migration activation energies.

The $\mathrm{AC}$ conductivity was calculated using the following equation,

$$
\sigma=\frac{Z^{\prime}}{Z^{\prime 2}+Z^{\prime \prime 2}} \cdot \frac{t}{A}
$$

(Equation 1)[33]

where Z' and Z' are the real and imaginary part of the impedance (ohms), A is the area of the sample $\left(\mathrm{m}^{2}\right)$ and $t$ is the sample thickness (m).

The real part of the relative permittivity, $\varepsilon$, was calculated using the following equation,

$$
\varepsilon=-\frac{Z^{\prime \prime}}{Z^{\prime 2}+Z^{\prime \prime 2}} \cdot \frac{t}{\omega \cdot A \cdot \varepsilon_{0}}
$$

(Equation 2)[33]

where $\omega$ is the angular frequency $=(2 \pi \mathrm{f})\left(\mathrm{s}^{-1}\right)$ and $\varepsilon_{0}$ is permittivity of free space $\left(\mathrm{F} \mathrm{m}^{-1}\right)$.

Finally, the phase angle $\theta$ between current and voltage was determined from the following equation:

$$
\theta=\tan ^{-1}\left(\frac{\mathrm{Z}^{\prime \prime}}{\mathrm{Z}^{\prime}}\right)
$$

(Equation 3)[33] 
3. Results and discussion

3.1. Chemical composition and morphology of chabazite powders

All three of the as-synthesised CHA zeolites were determined to be crystalline and phase pure chabazites by indexing of the powder X-ray diffractograms; these are shown in Figure 2.

\section{Position of Figure 2}

\section{Position of Caption for Figure 2}

The reflections of the XRD were indexed in the rhombohedral space group, $R \overline{3} m$, which is observed in the natural chabazite form [34]. The diffractograms of KCHA, CsCHA and ZnCHA match with diffractograms reported in the literature $[11,26,35]$. It should be noted it is known that upon cation exchange of KCHA to form $\mathrm{CsCHA}$ or $\mathrm{ZnCHA}$, a proportion of residual potassium cations remain in $\mathrm{CsCHA}$ and $\mathrm{ZnCHA} \mathrm{[36].}$ However, the resulting diffractograms of KCHA and CsCHA and ZnCHA do not show the presence of crystalline impurities and cation exchange did not greatly affect the observed spacings in the diffraction patterns.

3.2. Thermal stability of the synthesized chabazite powders

The thermal stability and dehydration of the three chabazites were examined by thermogravimetry analysis (TGA), from $21^{\circ} \mathrm{C}$ to $700^{\circ} \mathrm{C}$, as shown in Figure 3. It can be observed that the mass of all three materials decreased with increased temperature, which is attributed to the progressive removal of water molecules from different crystallographic sites. As shown in the works on natural chabazites by Fialips and Zema, different energetic types of water exist in these materials $[37,38]$. In all samples, dehydration began as soon as the temperature was raised, however the thermal stability and mass variations are different for each material. Indeed, the thermal behavior is linked to the nature of the extra-framework cations. For the three materials, the mass decrease between $25^{\circ} \mathrm{C}$ to $200{ }^{\circ} \mathrm{C}$, is ascribed to loss of water molecules with low bonding strengths to the structural frameworks. 


\section{Position of Caption for Figure 3}

While no other mass loss is observed for $\mathrm{CsCHA}$ after $200{ }^{\circ} \mathrm{C}$, it is not the same for $\mathrm{KCHA}$ and $\mathrm{ZnCHA}$. Between the temperature range $200{ }^{\circ} \mathrm{C}$ to $460{ }^{\circ} \mathrm{C}$ for $\mathrm{KCHA}$ and $200{ }^{\circ} \mathrm{C}$ to $550{ }^{\circ} \mathrm{C}$ for $\mathrm{ZnCHA}$, the TGA curves display an additional mass loss that may be related to the loss of water molecules that are bound more strongly to the framework. Similar TGA curves have been previously reported.[39] The maximum percentage weight loss is $11.1 \%$ for $\mathrm{CsCHA}, 18.6 \%$ for $\mathrm{KCHA}$ and $19.6 \%$ for $\mathrm{ZnCHA}$. The amount of $\mathrm{H}_{2} \mathrm{O}$ and the nature of the dehydration reaction appear to be controlled largely by the hydration energy of extra-framework cations. This is in agreement with results of Bish on clinoptilolite and heulandite [40]. The ionic hydration enthalpies for $\mathrm{Cs}^{+}, \mathrm{K}^{+}$and $\mathrm{Zn}^{2+}$ are $-264 \mathrm{~kJ} \mathrm{~mol}^{-1},-322 \mathrm{~kJ} \mathrm{~mol}^{-1}$ and $-2046 \mathrm{~kJ}^{\mathrm{mol}}{ }^{-1}$, respectively [41]. Therefore, due to the small hydration energy of $\mathrm{Cs}^{+}$, compared to $\mathrm{K}^{+}$and $\mathrm{Zn}^{2+}$, $\mathrm{CsCHA}$ is less hydrated at room temperature and completely dehydrates at a lower temperature.

After thermal analysis up to $700{ }^{\circ} \mathrm{C}$, the chabazite powders were again characterized by $\mathrm{X}$-ray diffractometry to check for changes in the structure upon dehydration. The diffractograms for each sample, collected before and after thermogravimetric analysis, are compared in Figure 4 below. Heating of the ionexchanged chabazites up to $700{ }^{\circ} \mathrm{C}$, followed by cooling, does not lead to decomposition and there is no evidence for loss of crystallinity or changes to the rhombohedral symmetry from the XRD. As in this work, Barrer did not observe significant modification of the chabazite structure as a function of degree of hydration [42].

\section{Position of Figure 4}

\section{Position of Caption for Figure 4}

\subsection{Electrical properties during heating}

The AC conductivity was measured experimentally by use of low-frequency impedance spectroscopy $(<1 \mathrm{MHz})$. The frequency dependent conductivity is usually expressed in the form of a universal dielectric response (UDR):

$$
\sigma(\omega)=\sigma(0)+A \omega^{\mathrm{s}}
$$


where $\sigma(0)$ is the low frequency conductivity, it is the DC conductivity, $\omega$ is angular frequency and A and $\mathrm{s}$ are constants, with $0<\mathrm{s}<1$; these two latter parameters are characteristic of the solid studied. The relative permittivity $(\varepsilon)$ also follows typically a power-law decay such that $\varepsilon \propto \omega^{s-1}$. This type of frequency response has been shown to be typical for a resistor-capacitor network (R-C) [46,43], and chabazite can be described in terms of its electrical response as a mixture of conductive regions (the resistors) and dielectric regions (the capacitors). At room temperature, as shown by thermogravimetry (Figure 3) and X-ray diffraction (Figure 4), adsorbed water exists in the chabazite structure and the water is coordinated with, and can modify the mobility of the cations. As proposed by Banys et al. [44], in mesoporous molecular sieve materials, water can be considered as the resistor and in hydrated chabazites, the insulating aluminosilicate framework structure of chabazite as the capacitor. Upon inclusion of water within the chabazite pores, the interaction of the cations with the anionic framework becomes weaker and the cations become more mobile in the applied electric field. Many authors have shown that residual water in the pores of zeolites can lead to increased conductivity [16,17].

The AC conductivity data for the three chabazite samples are shown in Figure 5. For clarity, only data at intervals of $100{ }^{\circ} \mathrm{C}$ are presented here. In the central range of frequencies $\left(10^{2}-10^{4} \mathrm{~Hz}\right)$ there is a 'plateau' in $\mathrm{AC}$ conductivity with a relatively low frequency dependence that is identified with the bulk DC conductivity. The plateaus in the conductivities of the material in this intermediate frequency range exhibit shallow power law increases with frequency, these are described as 'low frequency dispersions' [45]. At lower frequencies $\left(<10-10^{2} \mathrm{~Hz}\right)$, the $\mathrm{AC}$ conductivity falls due to electrode polarisation effects at the electrodes which block the carriers associated with conductivity. At high frequencies $\left(>10^{5} \mathrm{~Hz}\right)$ there is a power law increase in conductivity, that is explained by the high frequency dispersion of the universal dielectric response (Eqn. 4). The DC conductivity plateau in Figure 5 initially decreases as the temperature is increased and becomes less temperature dependent at temperatures above $110^{\circ} \mathrm{C}$; this decrease in conductivity with increasing temperature is likely to be a consequence of the loss of water within the structure of the hydrated chabazites. At the higher temperatures $\left(>110^{\circ} \mathrm{C}\right)$, where water has been removed from the materials structure, the frequency dependent properties are more representative of the materials itself. Electrode polarisation effects are observed at lower frequencies that correspond to a decrease in $\mathrm{AC}$ 
conductivity, especially for $\mathrm{KCHA}$ and $\mathrm{CsCHA}$ due the electrode blocking effect, and the AC conductivity typically becomes frequency dependent at frequencies above $10^{4} \mathrm{~Hz}$.

At room temperature, hydrated $\mathrm{KCHA}$ is the most conductive material and dehydrated $\mathrm{KCHA}$ is the most conductive at $710^{\circ} \mathrm{C}$. In addition, the same tendency is observed in the $\mathrm{AC}$ conductivity, as a function of temperature for all three chabazites (Figure 5). With increasing temperature, the values of conductivity decrease with increasing temperature before increasing to values beyond the initial room temperature values, as can be seen in Figure 5. This behaviour is less significant for $\mathrm{ZnCHA}$ for which the values at low temperature are similar. Gittings et al. attributed this 'hysteresis' behaviour to the removal of water at low temperatures for a hydroxyapatite material [47]. The thermal analyses (Figure 3) indicated a dehydration of $\mathrm{CsCHA}$ at a lower temperature than $\mathrm{KCHA}$ and ZnCHA. This trend was mirrored in the electrical measurement data - a lower critical temperature transition (from decreasing to increasing) for CsCHA than KCHA and ZnCHA was observed. This suggests that the hypothesis proposed by Gittings et al. on hydroxyapatatite can also be applied to chabazites.

Figure 6 shows the frequency dependent relative permittivity of the chabazite. Extremely large values of relative permittivity $\left(>10^{4}\right)$ are observed at low frequencies. Large values of relative permittivity at low frequencies, and their rapid decrease with frequency, is a consequence of the observed low frequency dispersion in AC conductivity and its related effect on dielectric loss [48]. In addition to the continuous percolation paths of conducting phase (water at low temperatures or ions at higher temperatures) there are numerous incomplete percolation paths where small quantities of a dielectric/insulating phase are present. These small quantities of the dielectric phase can act to block the path for DC conduction; thereby acting as microscale capacitors that lead to a large capacitance and high effective permittivity. At the highest frequencies the relative permittivity converges to a similar value since conduction is dominated by the capacitive displacement current contribution ( since $\omega \mathrm{C}>\mathrm{R}^{-1}$ ) and is less dependent on the presence of water on other conduction mechanisms in this higher frequency range. At room temperature, values of 42.9, 31.3 and 32.3 are attained at $1 \mathrm{MHz}$ for $\mathrm{KCHA}, \mathrm{CsCHA}$ and $\mathrm{ZnCHA}$ respectively. These values are higher than the relative permittivity value of 8.7 for mineral chabazite powder reported by Rozenholtz [49] and this may be due to the contribution of conductivity the permittivity magnitude. 
The phase shift, or phase angle $\theta$, is the difference in phase between $\mathrm{AC}$ current and voltage. In a purely conductive material (or a perfect resistor) the current and voltage are in phase $\left(\theta=0^{\circ}\right)$, while in a purely insulating material (or a perfect capacitor) the $\mathrm{AC}$ current lags $\mathrm{AC}$ voltage by $90^{\circ}\left(\theta=-90^{\circ}\right)$. The frequency dependence of the phase in Figure 7 for the three chabazites indicates the three materials are never purely conductive nor purely capacitive across the whole frequency range for the temperatures examined here; this is very similar to the behavior of lead halide perovskite solar cell materials or wet ferroelectrics [48]. The frequency dependence of the phase has small negative values at $\sim-10^{\circ}$ across the intermediate frequency range $\left(10^{3}-10^{5} \mathrm{~Hz}\right)$ where the 'plateau' in $\mathrm{AC}$ conductivity is located, indicating this region to be predominantly conductive and carrier based, but since the phase is not zero there is a small capacitive displacement current contribution. This is likely to be due to incomplete paths for conduction of water in the structure, or ions at higher temperatures.

At higher frequencies $\left(>10^{2}-10^{4} \mathrm{~Hz}\right)$ the phase drops to $-50^{\circ}$ or lower, which is consistent with the high frequency dispersion (Eqn. 4) that involves AC conduction throughout the bulk of the sample. The fall in phase angle moves to higher frequencies at the highest temperatures $\left(>400^{\circ} \mathrm{C}\right)$ due to a higher conductivity (Figure 5) and higher frequencies are therefore needed for the condition $\omega \mathrm{C}>\mathrm{R}^{-1}$, where there is a capacitive displacement current contribution. At the very low frequencies $\left(<10^{2} \mathrm{~Hz}\right)$ there is also a fall in phase, corresponding to the decrease in conductivity that results from electrode polarisation effects caused by blocking electrodes. The ZnCHA exhibits the least phase shift (Figure 7) and decrease in conductivity (Figure 5) at the lower frequencies due to electrode blocking effects compared to the other two chabazites. Electrode polarization, and the resulting fall in $\mathrm{AC}$ conductivity and rise in permittivity, originates from mobile ions arriving at the metallic electrodes and accumulating in thin layers just beneath the sample surface, thereby forming a 'space-charge region'[50]. The mobility in this region may be higher in the ZnCHA. Other factors influencing electrode polarisation include specimen geometry and electrode type, but these are the same for all materials evaluated.

Barrer et al. [21] did not report phase shift, but examined the loss angle $(\tan \delta)$ as a function of frequency and temperature for sodium chabazite. They observed a peak in the frequency dependence of $\tan \delta$ in the frequency range $10^{3}-10^{4} \mathrm{~Hz}$; which corresponds to the location of minimum phase shift observed in our results in Figure 7. They also reported that the peak in $\tan \delta$ moved to higher frequencies as the temperature was increased and is likely to be due to the same reasons outlined above. 
Position of Figure 5 (a), (b) and (c)

Position of Caption for Figure 5 (a), (b) and (c)

Position of Figure 6(a), (b) and (c)

Position of Caption for Figure 6(a), (b) and (c)

Position of Figure 7(a), (b) and (c)

Position of Caption for Figure 7(a), (b) and (c)

\subsection{Electrical properties during cooling}

At high temperature, there is no adsorbed water, as can be seen from the thermogravimetric analysis (Figure 3) and conductivity data (Figure 5). At high temperature, according to the R-C model, the 'resistors' can be considered as the ions participating in thermally activated hopping and the 'capacitors' can be considered as less mobile ions that could impede conduction. In this case the AC conductivity simply decreases with decreasing temperature due to the reduced number of thermally activated ions, see Figure 8. Below $210^{\circ} \mathrm{C}$ the pattern is less clear and this is likely to be due to the adsorption of water into the chabazite structure. Again, high permittivities are observed at low frequency due to conductivity (Figure 9). The frequency dependence of the phase in Figure 10 continues to have small negative values at $\sim-10^{\circ}$ across the intermediate frequency $\left(10^{3}-10^{5} \mathrm{~Hz}\right)$ range where the plateau in conductivity is found. At higher frequencies the phase drops $-50^{\circ}$ or lower due to the high frequency dispersion above that involves $\mathrm{AC}$ conduction throughout the bulk of the sample, and is similar during the heating cycle (Figure 7) for higher temperatures since the material is dehydrated for both conditions. The high frequency fall in phase is moved to lower frequencies on the cooling cycle in Figure 10 compared to Figure 7, since the material is less hydrated and has a lower conductivity; hence a lower frequency is needed for the condition $\omega \mathrm{C}>\mathrm{R}^{-1}$.

Position of Figure 8(a), (b) and (c)

Position of Caption for Figure 8(a), (b) and (c)

Position of Figure 9(a), (b) and (c)

Position of Caption for Figure 9(a), (b) and (c) 


\section{Position of Figure 10(a), (b) and (c)}

\section{Position of Caption for Figure 10(a), (b) and (c)}

\subsection{Activation energies for conduction}

It can be stated that $\sigma_{0}$ obeys the Arrhenius law:

$$
\sigma_{0=} \frac{B}{T} \exp \left(-\frac{E_{a}}{\Theta}\right)
$$

(Equation 5)

where $B$ is the pre-exponential factor, $E_{a}$ is the activation energy and $\Theta=\mathrm{k}_{\mathrm{B}} \mathrm{T}$, where $\mathrm{k}_{\mathrm{B}}$ is the Boltzmann constant. By plotting $\ln \sigma_{0}$ at $0.1 \mathrm{~Hz}$ versus $1000 / \mathrm{T}$ during the cooling process, when there is no water in the system, from $710^{\circ} \mathrm{C}$ to room temperature $\left(\sim 21^{\circ} \mathrm{C}\right)$ for each ion-exchanged chabazite, an estimation of the activation energy can be achieved. This is shown in Figure 11 for the three chabazites, with each exhibit distinct slope $=-\mathrm{E}_{\mathrm{a}} / \mathrm{k}_{\mathrm{B}}$. The activation energy $\left(\mathrm{E}_{\mathrm{a}}\right)$ was observed to decrease at lower temperatures $(<200$ ${ }^{\circ} \mathrm{C}$ ) and can be attributed to partial rehydration of the chabazites at low temperature; this behaviour has been observed by Mogensen and Skou [51]. and in Figure 8. Therefore, to calculate the values of $E_{a}$, whilst avoiding the affect for rehydration, only the data during cooling from $710{ }^{\circ} \mathrm{C}$ and $230{ }^{\circ} \mathrm{C}$ is considered.

The activation energy for conduction $E_{a}$ is a complex quantity that is the sum of $E_{d}$, the energy for the creation of a mobile carrier and $E_{\mathrm{m}}$, the energy required for ion migration from its trapping site and where $E_{d}<<E_{m}$, in zeolites. The term $E_{m}$ represents the cation steric and coulombic potential energy barriers that a particular ion has to overcome for diffusion through the lattice, by a sequence of successful jumps onto vacant sites.

The conduction activation energy $\left(\mathrm{E}_{\mathrm{a}}\right)$ for $\mathrm{KCHA}$, over the temperature range $710-230{ }^{\circ} \mathrm{C}$, is $(0.66 \pm 0.10)$ $\mathrm{eV}$. As the chabazite is fully exchanged, this is attributed to the activation energy of $\mathrm{K}^{+}$cations. The highest conductivity of $\mathrm{KCHA}$ is linked to the lowest activation energy. The activation energy for CsCHA, over the temperature range $710-230{ }^{\circ} \mathrm{C}$, is $(0.88 \pm 0.01) \mathrm{eV}$. This value is higher than the conduction activation energy of $\mathrm{KCHA}$, and is consistent with the lower measured conductivity. In the literature, the activation energy for cation transport in zeolites has been investigated, and it has been shown that $\mathrm{E}_{\mathrm{a}}$ is dependent on 
the nature of the cations $[21,30,52]$. Beattie [20] measured activation energies for dehydrated ionexchanged $\mathrm{K}^{+}$and $\mathrm{Cs}^{+}$chabazites, who also observed that the conductivity of Cs-exchanged chabazite was lower than K-exchanged chabazite, and the conduction activation energy for Cs-exchanged chabazite was also higher than the conduction activation energy for K-exchanged chabazite. The ionic radius of $\mathrm{Cs}^{+}$ $(0.167 \mathrm{~nm})$ is higher than that of $\mathrm{K}^{+}(0.138 \mathrm{~nm})$, thus compared to $\mathrm{K}^{+}$the coulombic attraction between $\mathrm{Cs}^{+}$ ions and the lattice decreases, but the effect of cation-cation repulsions and steric effects would impede the hopping of $\mathrm{Cs}^{+}$ions along the channels within the framework. Thus this explains the higher conduction activation energy for $\mathrm{Cs}^{+}$than $\mathrm{K}^{+}$.

The activation energy for $\mathrm{ZnCHA}$, over the temperature range $710-230^{\circ} \mathrm{C}$, is slightly (i.e. $0.90 \pm 0.01 \mathrm{eV}$ ) larger than the conduction activation energy for $\mathrm{Cs}^{+}$in $\mathrm{CsCHA}$. The activation energy for $\mathrm{ZnCHA}$, over the temperature range $710-230{ }^{\circ} \mathrm{C}$, is significantly larger than the activation energy for $\mathrm{KCHA}$, despite $\mathrm{K}^{+}$and $\mathrm{Zn}^{2+}$ locating in $6 \mathrm{MR}$ sites in the respective chabazites. Compared to the $\mathrm{K}^{+}$cation, each $\mathrm{Zn}^{2+}$ cation is associated with two aluminium ions and $\mathrm{Zn}^{2+}$ has the smaller relative ionic radius $(0.074 \mathrm{~nm})$, thus the coulombic interaction with the framework is much stronger, and thus is proposed to be the reason why the conduction activation energy is higher. In corroboration, it has been demonstrated that activation energies are higher for divalent cations compared to monovalent cations in Y-type faujasites [53].

\section{Position of Figure 11(a), (b) and (c)}

Position of Caption for Figure 11(a), (b) and (c)

\section{Conclusions}

The extra-framework cations within chabazites exhibit an interesting 'trapdoor' phenomenon upon interaction with guest gas molecules, therefore this holds promise for use of these materials as selective sensing materials in next generation electrical-based gas sensors. To fully understand the fundamental electrical properties of some chabazites that have exhibited the 'trapdoor' effect, this paper provides a detailed characterisation of the frequency dependent conductivity and permittivity of chabazite materials. Although previous studies have been devoted to electrical properties of zeolites, comparison is difficult as the methods of preparation, the elemental composition and hydration of the compounds are often poorly detailed. The synthesis and characterisation of three ion-exchanged chabazites, KCHA, CsCHA and 
$\mathrm{ZnCHA}$, along with the electrical behaviour of the zeolites as a function of the temperature was presented. Due to the influence of hydration of the electrical properties the materials was thermally cycled to assess the material in the hydrated and dehydrated state. This was complemented with thermogravimetric studies. The CsCHA exhibited the lowest hydration level for measurements of mass loss during heating, this was also observed in the electrical measurements since the $\mathrm{CsCHA}$ material exhibited the lowest $\mathrm{AC}$ conductivity at room temperature. Upon heating, the initial decrease in AC conductivity was associated with water loss and the increase in conductivity at higher temperatures was associated with improved ionic conductivity. The materials exhibited the universal dielectric response which is typical of materials consisting of both conductive and insulating regions, typical of a resistor-capacitor (R-C) network, where regions of adsorbed water or ions participating in thermally activated hopping are the 'resistors' and regions of the aluminosilcate framework backbone act as 'capacitors'. Due to porosity the three chabazites were hydrated significantly at room temperature, thus in order to make assertions about the alkali metal cation conduction in these materials, it was necessary to investigate the samples in the dehydrated state during cooling from high temperatures. The dehydrated state was achieved by heating the chabazites to a high temperature - heating to $710{ }^{\circ} \mathrm{C}$ ensured that all different energetic types of water were removed and guaranteed a crystallised sample with a rhombohedral symmetry. Activation energies for KCHA $(0.66 \pm$ $0.10) \mathrm{eV}$, CsCHA $(0.88 \pm 0.01) \mathrm{eV}$ and $\mathrm{ZnCHA}(0.90 \pm 0.01) \mathrm{eV}$ were determined. KCHA is a fullyexchanged chabazite with only $\mathrm{K}^{+}$cations as the extra-framework cations, whereas in the case of CsCHA and $\mathrm{ZnCHA}$, residual $\mathrm{K}^{+}$cations are present in addition to $\mathrm{Cs}^{+}$and $\mathrm{Zn}^{2+}$ cations, respectively (Table S1, Supplementary Information). However, despite this, the global density of cations in the three chabazites is almost the same. Furthermore, $\mathrm{Cs}^{+}$and $\mathrm{Zn}^{2+}$ cations are less mobile than $\mathrm{K}^{+}$and hamper the hopping of residual $\mathrm{K}^{+}$cations via the conduction paths. The electrical properties of all three chabazites below $200{ }^{\circ} \mathrm{C}$ were strongly influenced by hydration.. Overall, it was determined that when either hydrated or dehydrated, KCHA had the highest conductivity and lowest cation migration activation energy of the three studied chabazites and thus has the most promising electrical properties for potential use as a gas sensing material in next-generation electrical-based gas sensors.

Acknowledgements: AJWP and VPT thank the Engineering and Physical Sciences Research Council (EPSRC) for funding the research (H2FC SUPERGEN EP/E040071/1) and to the University of Bath for a Prize Research Fellowship for VPT and providing facilities. Financial support from Materials for Energy Efficiency in Transport (MEET), funded by the European Regional Development Fund (ERDF) 
INTERREG IV programme, is acknowledged (DJW). CRB would like to acknowledge funding from the European Research Council under the European Union's Seventh Framework Programme (FP/2007-2013) / ERC Grant Agreement no. 320963 on Novel Energy Materials, Engineering Science and Integrated Systems (NEMESIS). HD acknowledges funding from the Vietnamese Government in the form of a Vietnamese Government Scholarship and HB acknowledges the Erasmus Programme. Original data and analysis are deposited here: $\underline{\text { https://doi.org/10.15125/BATH-00402 }}$

Conflict of Interest: The authors declare that they have no conflict of interest.

\section{References}

[1] C. Baerlocher, L.B. McCusker, D. Olson, W.M. Meier, International Zeolite Association. Structure Commission., Atlas of Zeolite Framework Types, Published on behalf of the Structure Commission of the International Zeolite Association by Elsevier, 2007.

[2] B. Jha, D.N. Singh, in:, B. Jha, D.N. Singh (Eds.), Fly-Ash Zeolites: Innovation, Application and Direction, Springer Science + Business Media, Singapore, 2016, p. 211.

[3] J. Gao, M. Liu, X. Wang, X. Guo, Ind. Eng. Chem. Res. 49 (2010) 2194-2199.

[4] T. Maesen, in:, J. Čejka, H. van Bekkum, A. Corma, F. Schüth (Eds.), Introduction to Zeolite Science and Practise Vol. 168, 3rd ed., Elsevier, 2007, pp. 1-12.

[5] D.J. Wales, J. Grand, V.P. Ting, R.D. Burke, K.J. Edler, C.R. Bowen, S. Mintova, A.D. Burrows, Chem. Soc. Rev. 44 (2015) 4290-4321.

[6] D.S. Coombs, A. Alberti, T. Armbruster, G. Artioli, C. Colella, E. Galli, J.D. Grice, F. Liebau, J.A. Mandarino, H. Minato, E.H. Nickel, E. Passaglia, D.R. Peacor, S. Quartieri, R. Rinaldi, M. Ross, R.A. Sheppard, E. Tillmans, G. Vezzalini, Can. Mineral. 35 (1997) 1571-1606.

[7] T.R. Gaffney, in:, H. Robson (Ed.), Verified Synthesis of Zeolitic Materials, 2nd ed., 2001, pp. $123-125$.

[8] B. Civalleri, A.M. Ferrari, M. Llunell, R. Orlando, M. Mérawa, P. Ugliengo, Chem. Mater 15 (2003) 3996-4004.

[9] J. Shang, G. Li, R. Singh, Q. Gu, K.M. Nairn, T.J. Bastow, N. Medhekar, C.M. Doherty, A.J. Hill, P.A. Webley, J. Am. Chem. Soc. 134 (2012) 19246-19253.

[10] J. Shang, G. Li, R. Singh, P. Xiao, D. Danaci, J.Z. Liu, P.A. Webley, J. Chem. Phys. 140 (2014) 84705.

[11] A.J.W. Physick, D.J. Wales, S.H.R. Owens, J. Shang, P.A. Webley, T.J. Mays, V.P. Ting, Chem. Eng. J. 288 (2016) 161-168.

[12] A. Alberti, E. Galli, G. Vezzalini, E. Passaglia, P.F. Zanazzi, Zeolites 2 (1982) 303-309.

[13] M. Calligaris, A. Mezzetti, G. Nardin, L. Randaccio, Zeolites 6 (1986) 137-141.

[14] M. Kong, Z. Liu, T. Vogt, Y. Lee, Microporous Mesoporous Mater. 221 (2016) 253-263.

[15] L.A.M.M. Barbosa, R.A. van Santen, J. Hafner, J. Am. Chem. Soc. 123 (2001) 4530-4540.

[16] D.N. Stamires, J. Chem. Phys. 36 (1962) 3174.

[17] A. Abdoulaye, G. Chabanis, J.C. Giuntini, J. Vanderschueren, J.V. Zanchetta, F. Di Renzo, J. Phys. Chem. B 101 (1997) 1831-1836.

[18] A. Abdoulaye, J.. Zanchetta, F. Di Renzo, J.. Giuntini, J. Vanderschueren, G. Chabanis, Microporous Mesoporous Mater. 34 (2000) 317-325.

[19] D.C. Freeman, D.N. Stamires, J. Chem. Phys. 35 (1961) 799.

[20] A. Abdoulaye, S.S. Soulayman, G. Chabanis, J.C. Giuntini, J.V. Zanchetta, Microporous Mater. 8 (1997) 63-68.

[21] U. Simon, U. Flesch, J. Porous Mater. 6 (1999) 33-40.

[22] E. Rabinowitsch, W.C. Wood, Berichte Der Bunsengesellschaft Für Phys. Chemie 39 (1933) 562-566. 
[23] I.R. Beattie, Trans. Faraday Soc. 50 (1954) 581.

[24] R.M. Barrer, P.J. Coen, Nature 199 (1963) 587-588.

[25] J. Kjær, E. Skou, Solid State Ionics 40 (1990) 121-124.

[26] T. Du, S. Che, L. Liu, X. Fang, Res. Chem. Intermed. 43 (2017) 1783-1792.

[27] K. Sahner, G. Hagen, D. Schönauer, S. Reiß, R. Moos, Solid State Ionics 179 (2008) 2416-2423.

[28] A. Weiss, N. Reimer, N. Stock, M. Tiemann, T. Wagner, Microporous Mesoporous Mater. 220 (2016) 39-43.

[29] S. Galioglu, I. Cam, B. Akata, Microporous Mesoporous Mater. 250 (2017) 177-185.

[30] R.A. Schoonheydt, J.B. Uytterhoeven, in:, E.M. Flanigen, L.B. Sand (Eds.), Molecular Sieve Zeolites-I, 1974, pp. 456-472.

[31] M. Severance, Y. Zheng, E. Heck, P.K. Dutta, J. Phys. Chem. A 117 (2013) 13704-13711.

[32] M. Bourgogne, J.-L. Guth, R. Wey, Process for the Preparation of Synthetic Zeolites, and Zeolites Obtained by Said Process, US Patent 4,503,024, 4,503,024, 1985.

[33] C.R. Bowen, S. Buschhorn, V. Adamaki, Pure Appl. Chem. 86 (2014) 765-774.

[34] G. Montagna, S. Bigi, P. Kónya, S. Szakáll, G. Vezzalini, Am. Mineral. 95 (2010).

[35] J. Shang, G. Li, R. Singh, P. Xiao, J.Z. Liu, P.A. Webley, J. Phys. Chem. C 114 (2010) 2202522031.

[36] S.-H. Shim, A. Navrotsky, T.R. Gaffney, J.E. MacDougall, Am. Mineral. 84 (1999) 1870-1882.

[37] C.I. Fialips, J.W. Carey, D.L. Bish, Geochim. Cosmochim. Acta 69 (2005) 2293-2308.

[38] M. Zema, S.C. Tarantino, G. Montagna, Chem. Mater. 20 (2008) 5876-5887.

[39] H. Aysan, S. Edebali, C. Ozdemir, M. Celik Karakaya, N. Karakaya, Microporous Mesoporous Mater. 235 (2016) 78-86.

[40] D. Bish, in:, D. Kalló, H.S. Sherry (Eds.), Occurance, Properties and Utilisation of Natural Zeolites, Akadémiai Kiadó, Budapest, 1988, pp. 565-576.

[41] D.W. Smith, J. Chem. Educ. 54 (1977) 540.

[42] R.M. Barrer, J. Chem. Soc. (1950) 2342-2350.

[43] C.R. Bowen, D.P. Almond, Mater. Sci. Technol. 22 (2006) 719-724.

[44] M. Kinka, J. Banys, J. Macutkevic, A. Meskauskas, Electrochim. Acta 51 (2006) 6203-6206.

[45] A.K. Jonscher, Philos. Mag. Part B 38 (1978) 587-601.

[46] D.P. Almond, B. Vainas, J. Phys. Condens. Matter 11 (1999) 9081-9093.

[47] J.P. Gittings, C.R. Bowen, A.C.E. Dent, I.G. Turner, F.R. Baxter, J.B. Chaudhuri, Acta Biomater. 5 (2009) 743-754.

[48] D.P. Almond, C.R. Bowen, J. Phys. Chem. Lett. 6 (2015) 1736-1740.

[49] J.L. Rosenholtz, D.T. Smith, Am. Mineral. 21 (1936) 115-120.

[50] S. Emmert, M. Wolf, R. Gulich, S. Krohns, S. Kastner, P. Lunkenheimer, A. Loidl, Eur. Phys. J. B 83 (2011) 157-165.

[51] N.H. Mogensen, E. Skou, Solid State Ionics 77 (1995) 51-54.

[52] H.O. Pastore, E.C. Oliveira, A. Frache, S.R. Dutra, E. Boccaleri, L. Marchese, in:, E. van Steen, L.H. Callanan, M. Claeys (Eds.), Studies in Surface Science and Catalysis Vol. 154 Part B, Elsevier, 2004, pp. 1426-1430.

[53] I.M. Kalogeras, A.B. Vassilikou-Dova, in:, D.J. Fisher (Ed.), Defects and Diffusion in Ceramics, Trans Tech Publications, 1998, pp. 1-36. 


\section{Figure Captions:}

Figure 1: Framework diagram of a chabazite zeolite. Orange $=\mathrm{Si}$ or $\mathrm{Al}$, grey $=\mathrm{O}$. a) The three different types of rings: $4 \mathrm{MR}=$ red, $6 \mathrm{DR}=$ blue, $8 \mathrm{MRs}=$ peach. b) The four cation site preferences

Figure 2: X-ray powder diffraction patterns of CsCHA (blue), KCHA (orange) and ZnCHA (green)

Figure 3: TGA curves of $\mathrm{KCHA}, \mathrm{CsCHA}$ and $\mathrm{ZnCHA}$ when heating from $21{ }^{\circ} \mathrm{C}$ to $700{ }^{\circ} \mathrm{C}$

Figure 4: Comparison of X-ray powder diffraction pattern before and after thermal analyses for CsCHA,

$$
\mathrm{KCHA} \text { and } \mathrm{ZnCHA}
$$

Figure 5: AC conductivity versus frequency during heating for (a) $\mathrm{KCHA}$ (b) $\mathrm{CsCHA}$ (c) $\mathrm{ZnCHA}$. For all three plots: $30{ }^{\circ} \mathrm{C}=$ red circle; $110{ }^{\circ} \mathrm{C}=$ green circle; $210^{\circ} \mathrm{C}$ yellow triangle; $310{ }^{\circ} \mathrm{C}=$ blue triangle; 410 ${ }^{\circ} \mathrm{C}=$ pink square; $510{ }^{\circ} \mathrm{C}=$ cyan square; $610{ }^{\circ} \mathrm{C}=$ grey diamond and $710{ }^{\circ} \mathrm{C}=$ brown diamond.

Figure 6: Relative permittivity versus frequency during heating for (a) $\mathrm{KCHA}$ (b) $\mathrm{CsCHA}(\mathrm{c}) \mathrm{ZnCHA}$. For all three plots: $30^{\circ} \mathrm{C}=$ red circle; $110^{\circ} \mathrm{C}=$ green circle; $210{ }^{\circ} \mathrm{C}$ yellow triangle; $310{ }^{\circ} \mathrm{C}=$ blue triangle; $410{ }^{\circ} \mathrm{C}=$ pink square; $510{ }^{\circ} \mathrm{C}=$ cyan square; $610^{\circ} \mathrm{C}=$ grey diamond and $710{ }^{\circ} \mathrm{C}=$ brown diamond.

Figure 7: Phase angle versus frequency during heating for (a) KCHA (b) CsCHA (c) ZnCHA. For all three plots: $30^{\circ} \mathrm{C}=$ red circle; $110^{\circ} \mathrm{C}=$ green circle; $210{ }^{\circ} \mathrm{C}$ yellow triangle; $310{ }^{\circ} \mathrm{C}=$ blue triangle; 410 ${ }^{\circ} \mathrm{C}=$ pink square; $510{ }^{\circ} \mathrm{C}=$ cyan square; $610^{\circ} \mathrm{C}=$ grey diamond and $710{ }^{\circ} \mathrm{C}=$ brown diamond.

Figure 8: AC conductivity versus frequency during cooling for (a) $\mathrm{KCHA}$ (b) $\mathrm{CsCHA}$ (c) $\mathrm{ZnCHA}$. For all three plots: $30^{\circ} \mathrm{C}=$ red circle; $110^{\circ} \mathrm{C}=$ green circle; $210^{\circ} \mathrm{C}$ yellow triangle; $310^{\circ} \mathrm{C}=$ blue triangle; 410 ${ }^{\circ} \mathrm{C}=$ pink square; $510{ }^{\circ} \mathrm{C}=$ cyan square; $610^{\circ} \mathrm{C}=$ grey diamond and $710{ }^{\circ} \mathrm{C}=$ brown diamond. 
Figure 9: Relative permittivity versus frequency during cooling for (a) $\mathrm{KCHA}$ (b) $\mathrm{CsCHA}$ (c) $\mathrm{ZnCHA}$. For all three plots: $30^{\circ} \mathrm{C}=$ red circle; $110{ }^{\circ} \mathrm{C}=$ green circle; $210{ }^{\circ} \mathrm{C}$ yellow triangle; $310{ }^{\circ} \mathrm{C}=$ blue triangle; $410{ }^{\circ} \mathrm{C}=$ pink square $; 510^{\circ} \mathrm{C}=$ cyan square; $610^{\circ} \mathrm{C}=$ grey diamond and $710{ }^{\circ} \mathrm{C}=$ brown diamond.

Figure 10: Phase angle versus frequency during cooling for (a) KCHA (b) CsCHA (c) ZnCHA. For all three plots: $30{ }^{\circ} \mathrm{C}=$ red circle; $110{ }^{\circ} \mathrm{C}=$ green circle; $210^{\circ} \mathrm{C}$ yellow triangle; $310{ }^{\circ} \mathrm{C}=$ blue triangle; 410 ${ }^{\circ} \mathrm{C}=$ pink square; $510^{\circ} \mathrm{C}=$ cyan square; $610^{\circ} \mathrm{C}=$ grey diamond and $710^{\circ} \mathrm{C}=$ brown diamond.

Figure 11: Arrhenius plot of natural $\log (\ln )$ of bulk conductivity (cond.) multiplied by temperature (temp.), against 1000/T, for (a) KCHA, (b) CsCHA and (c) ZnCHA 


\section{Figures:}

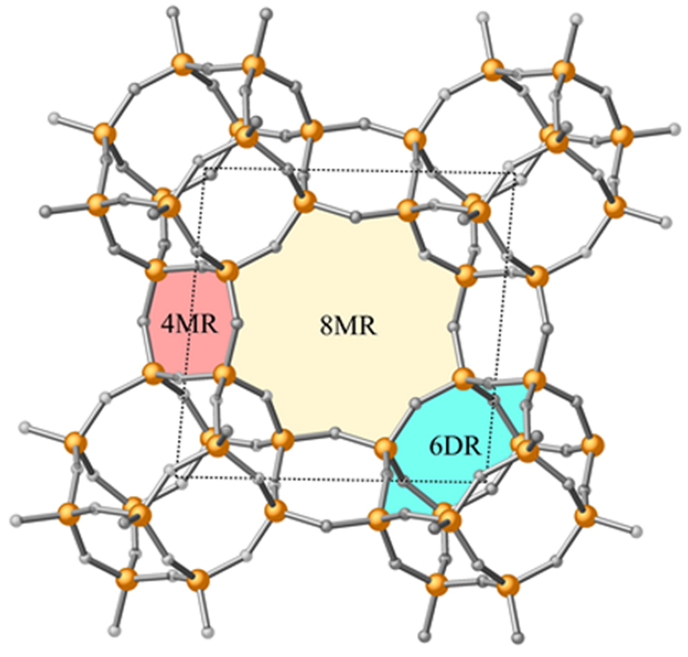

a)

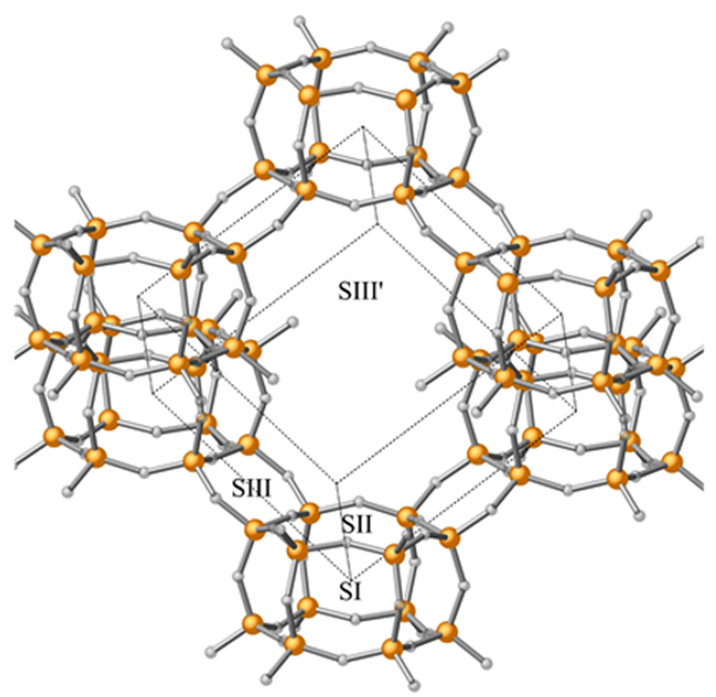

b)

Figure 1(a) and (b)

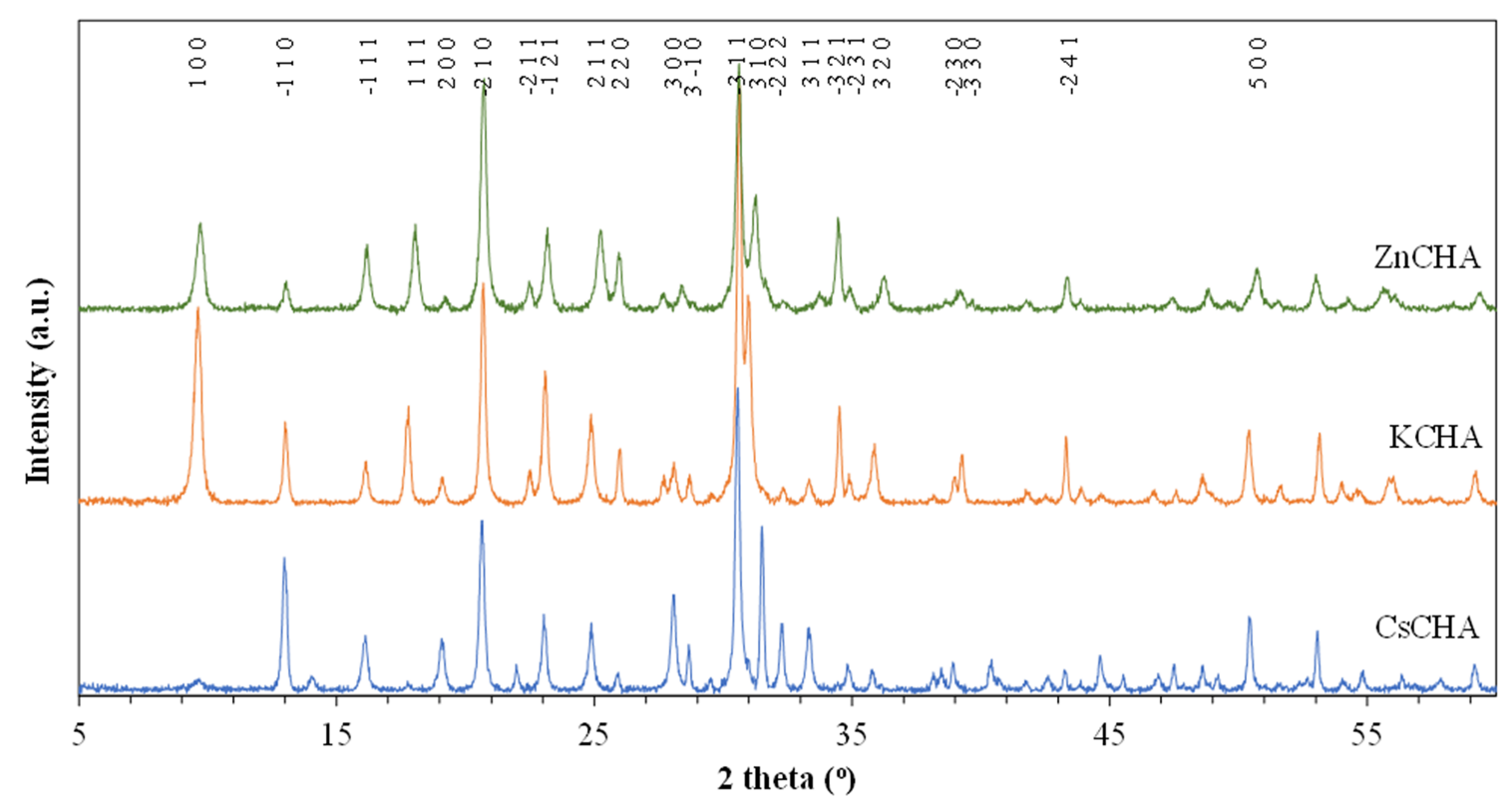

Figure 2 


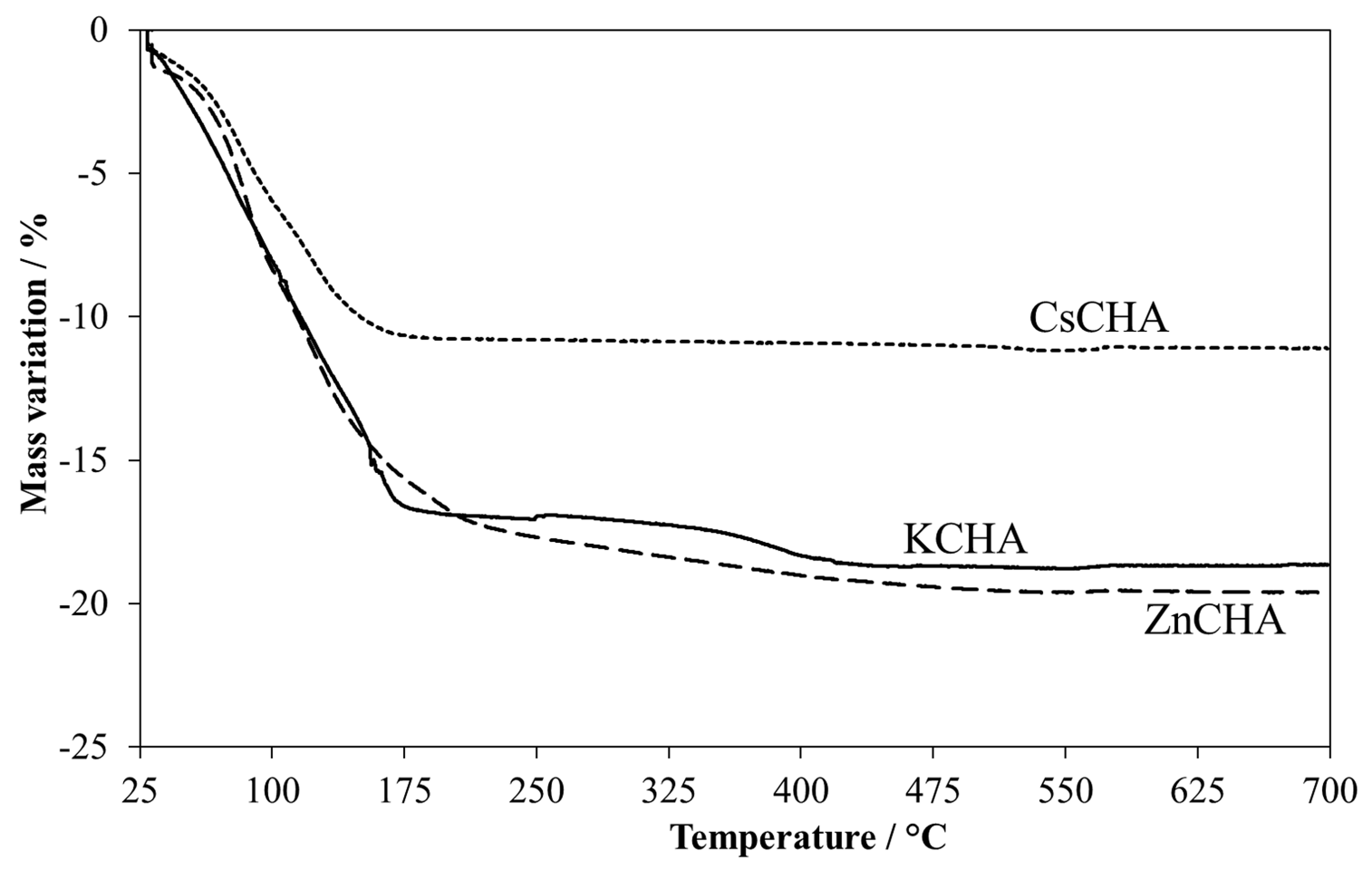

Figure 3

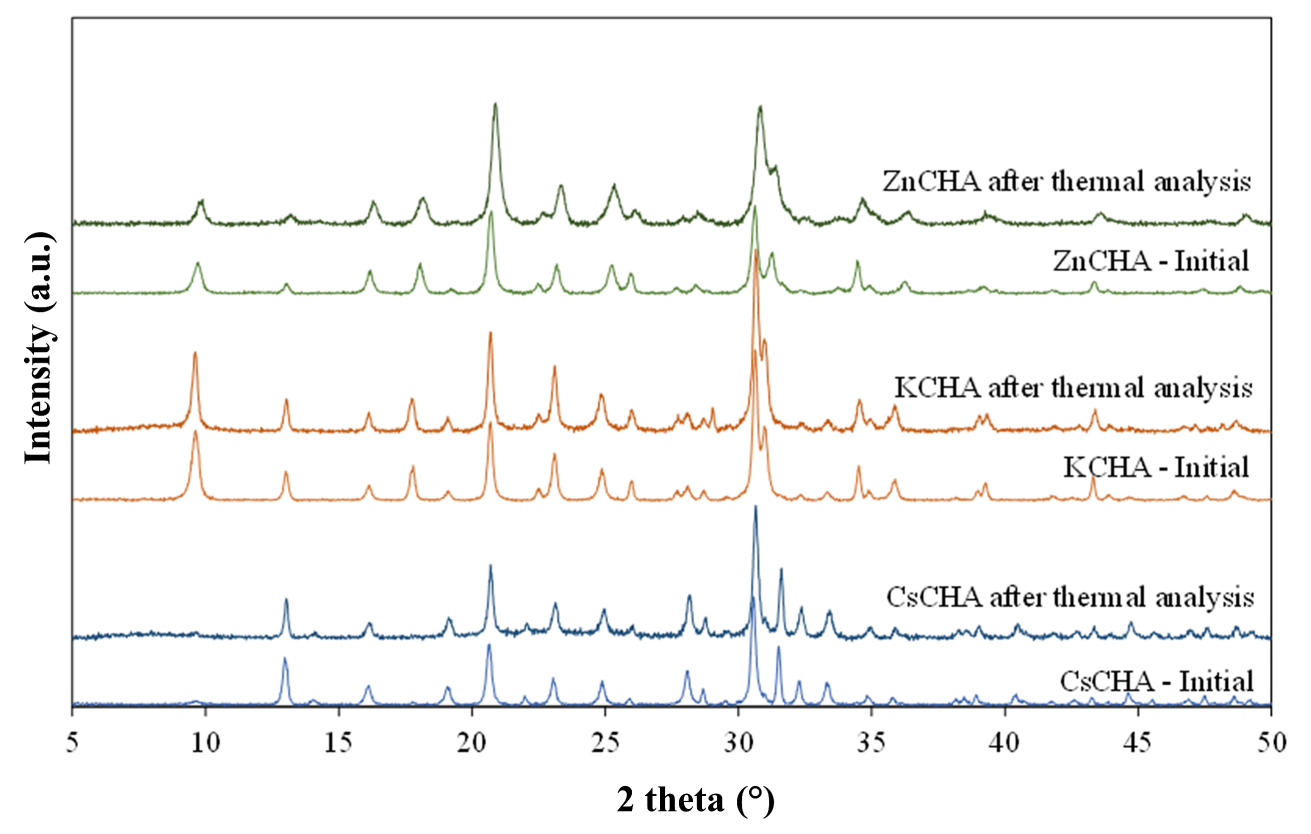

Figure 4 

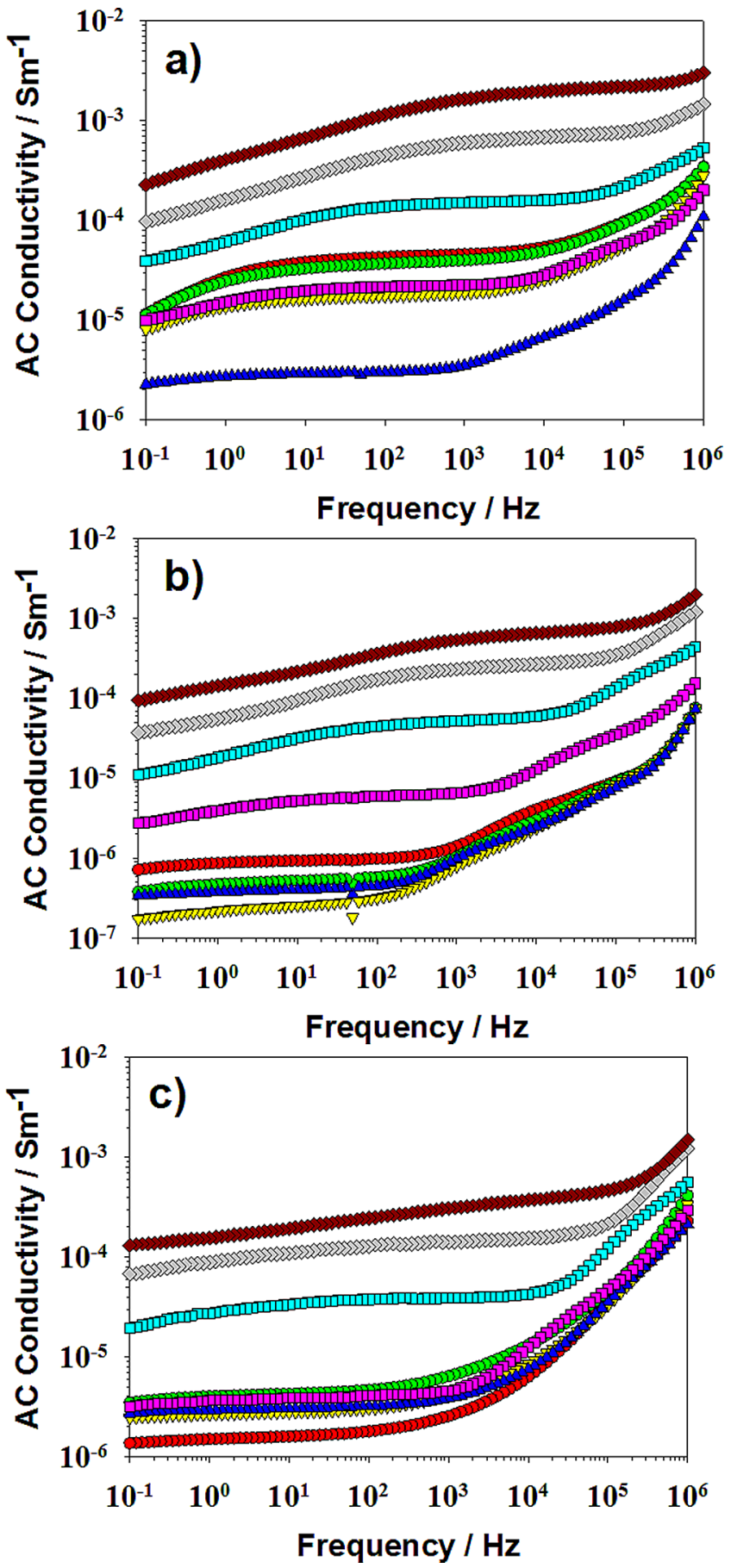

Figure 5(a), (b) and (c) 

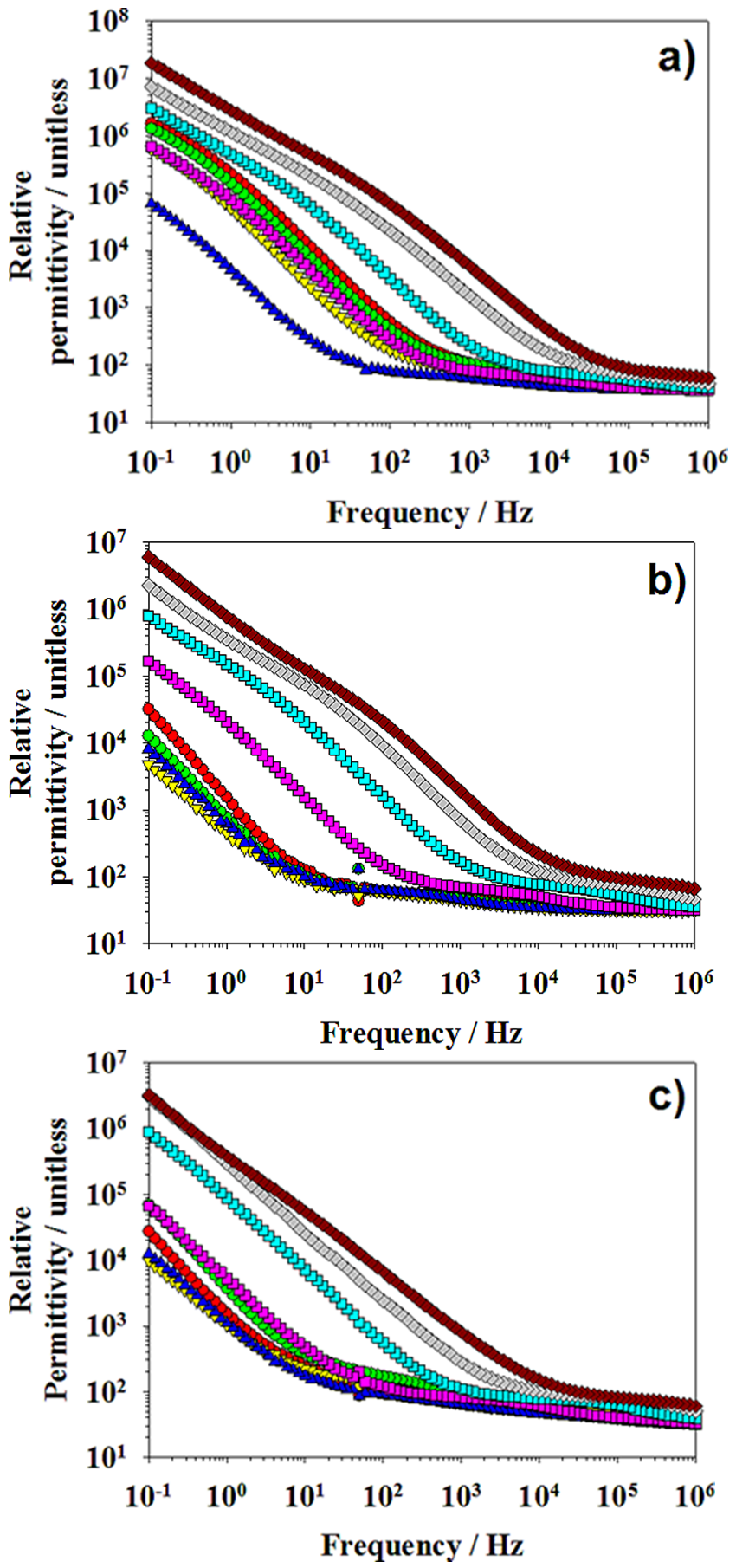

Figure 6(a), (b) and (c) 

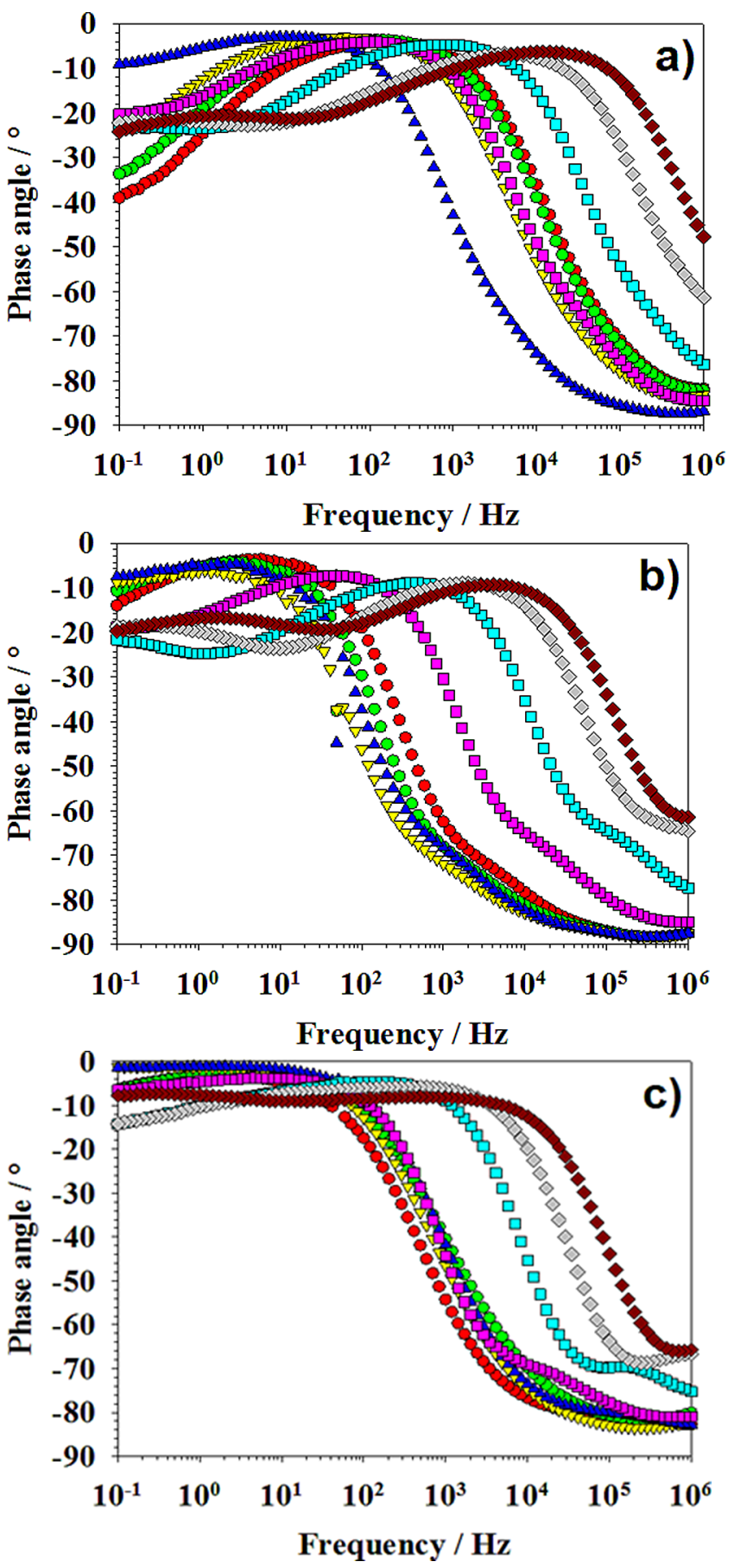

Figure 7(a), (b) and (c) 

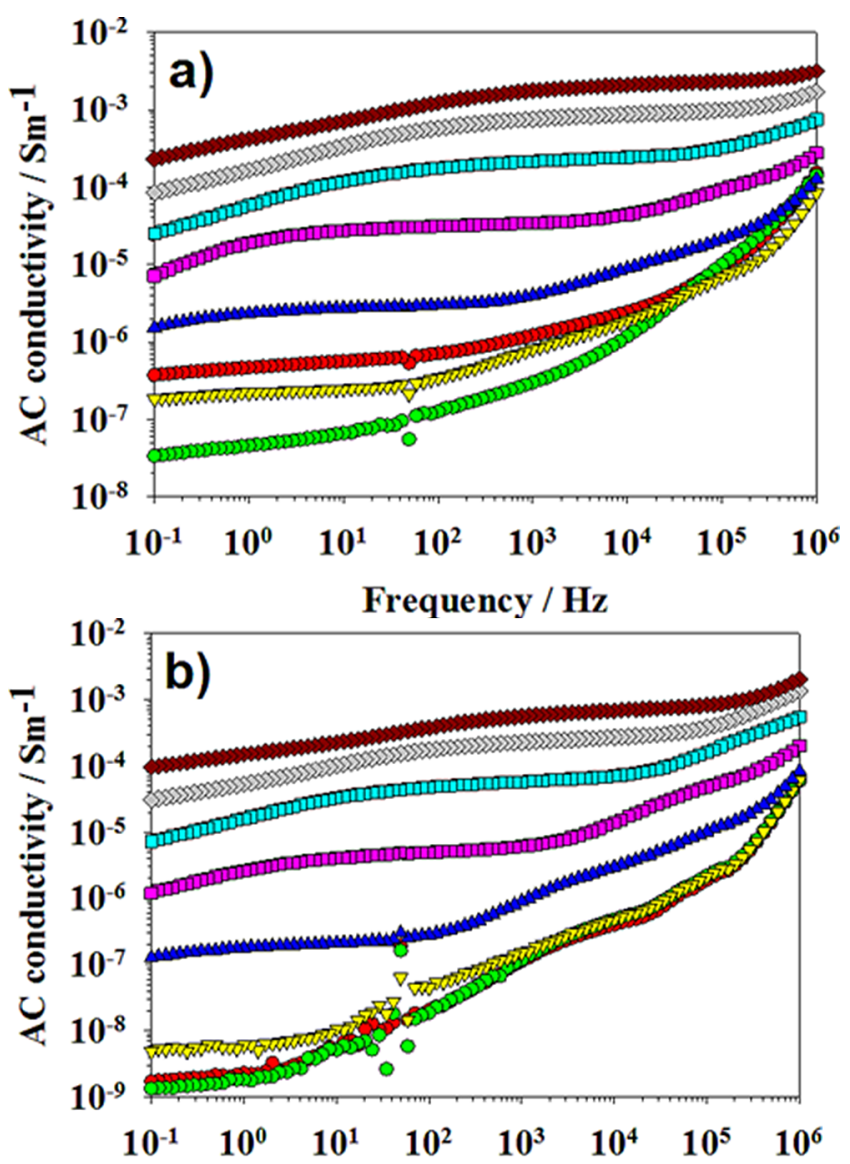

Frequency / $\mathrm{Hz}$

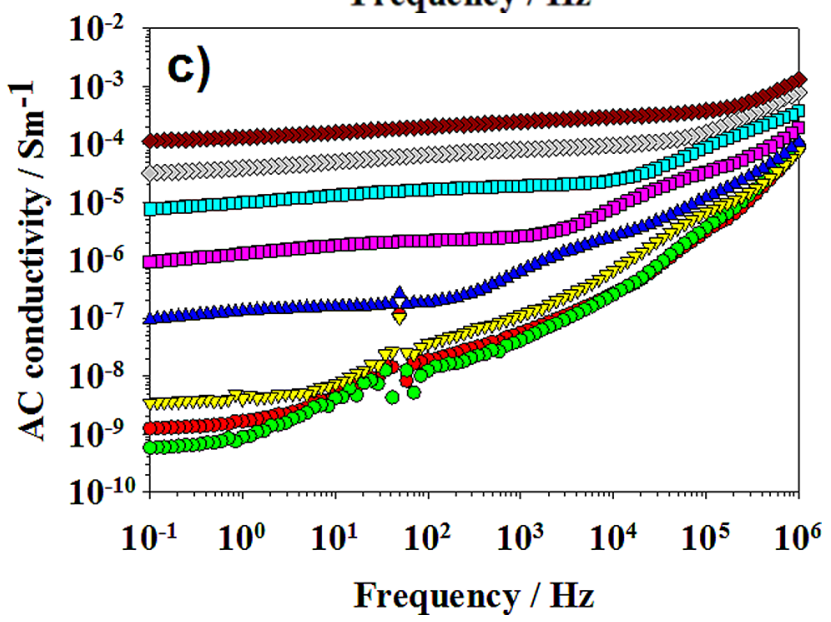

Figure 8(a), (b) and (c) 

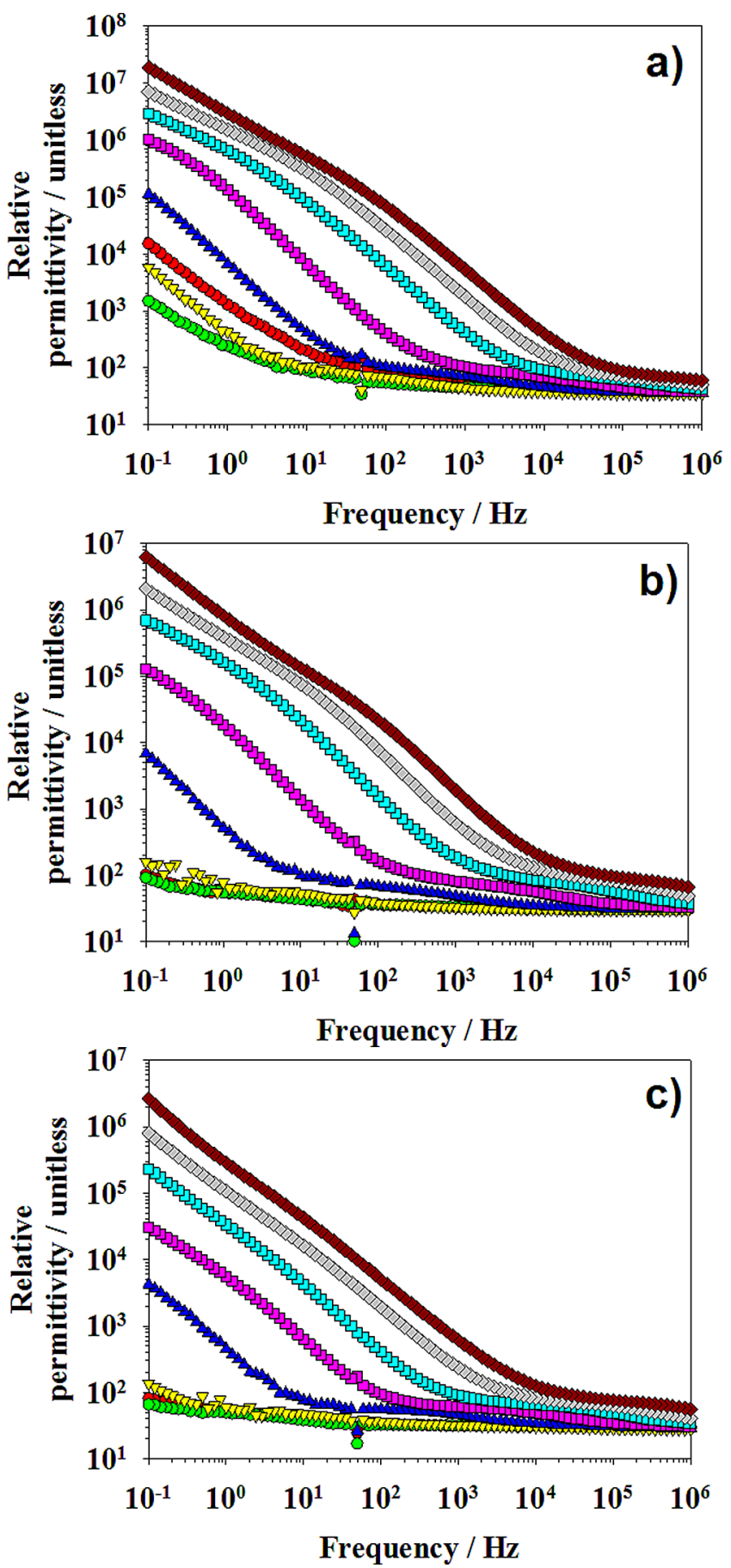

Figure 9(a), (b) and (c) 

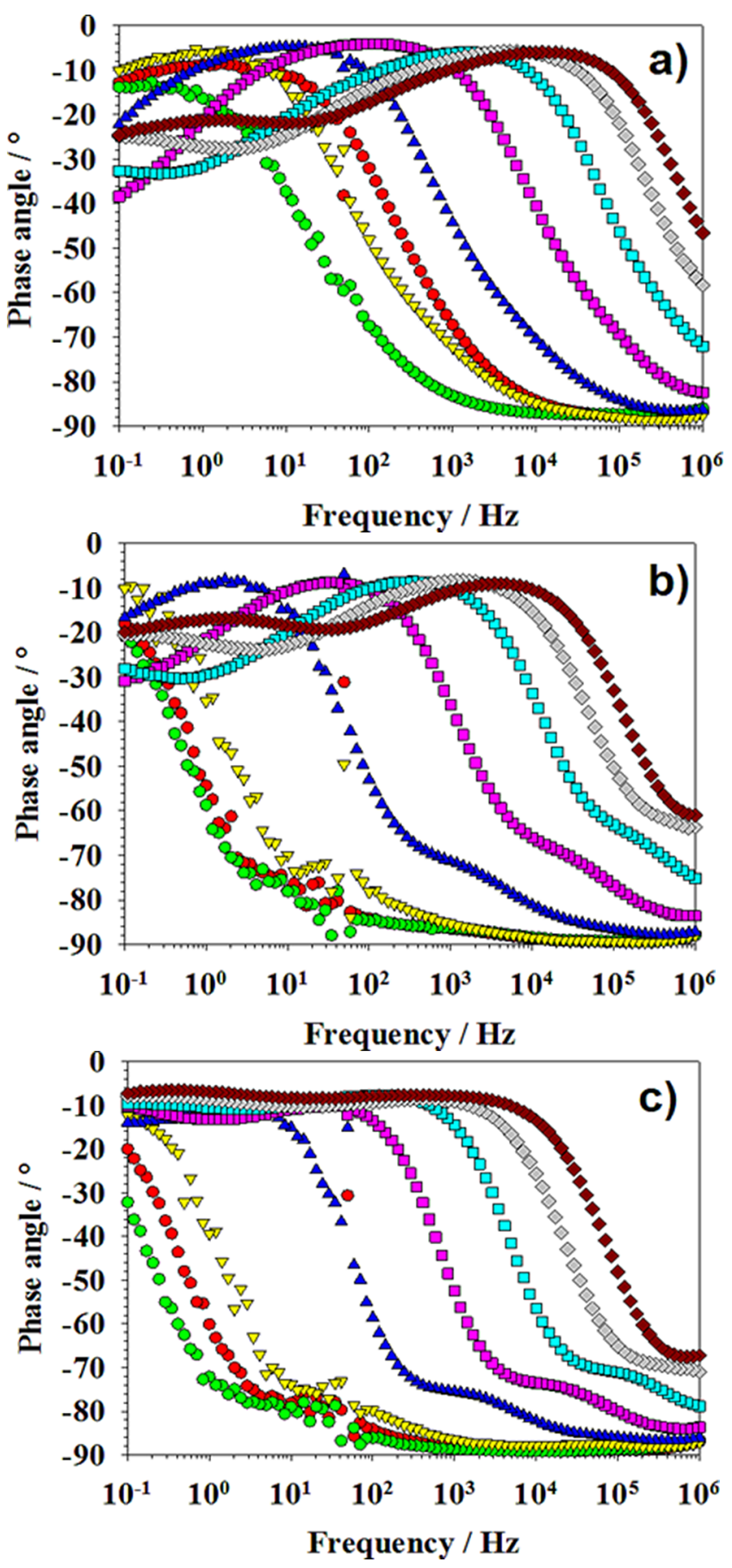

Figure 10(a), (b) and (c) 

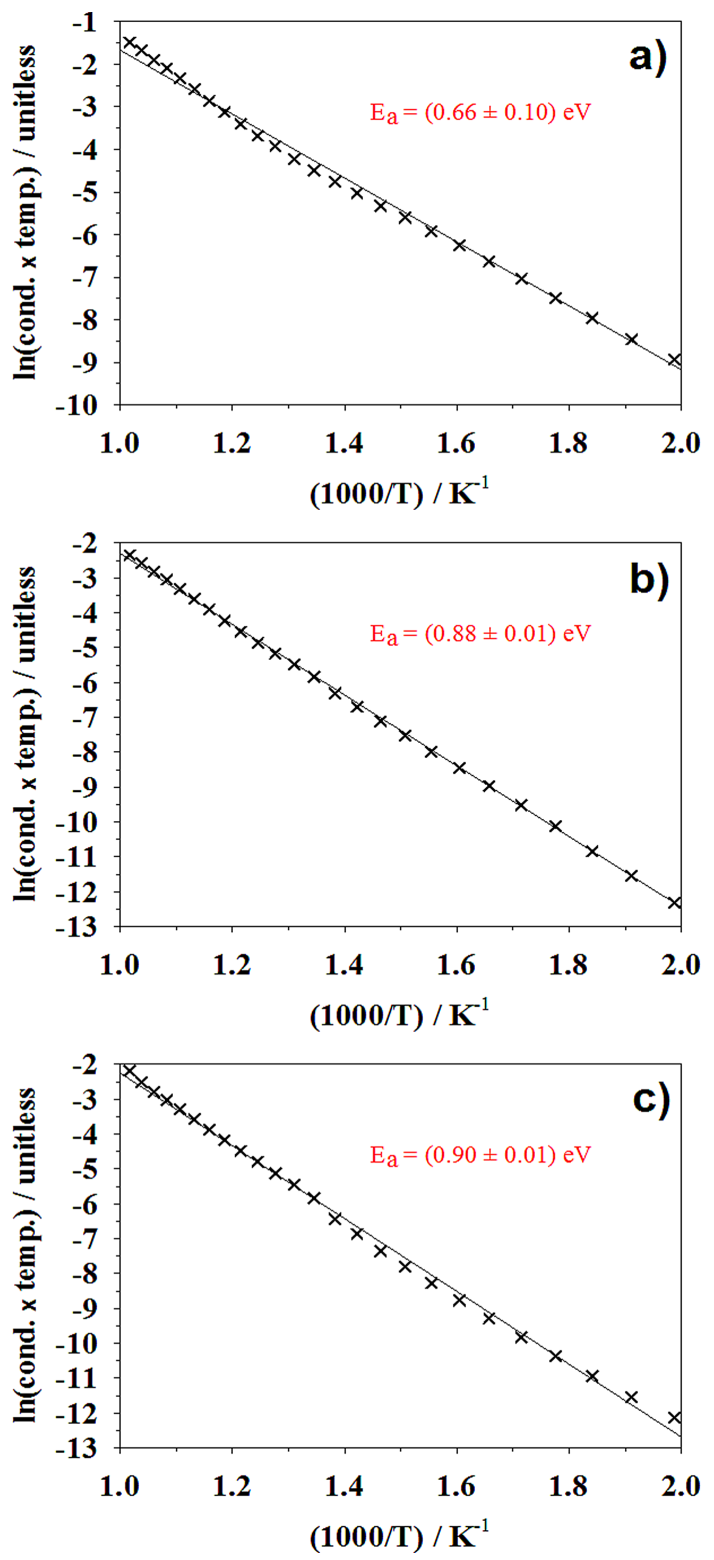

Figure 11(a), (b) and (c) 